
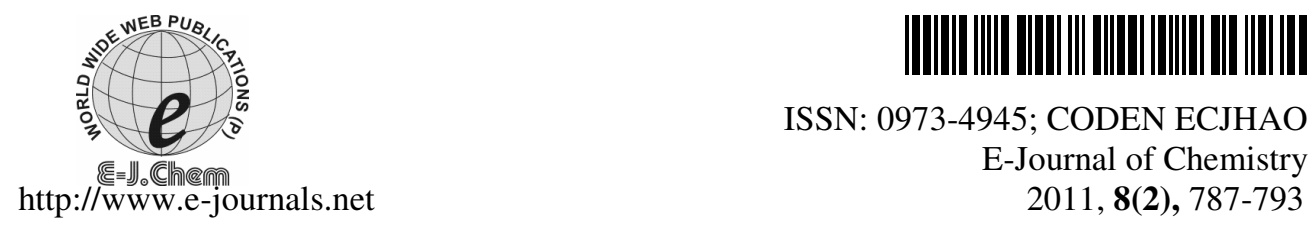

ISSN: 0973-4945; CODEN ECJHAO

E-Journal of Chemistry

2011, 8(2), 787-793

\title{
Groundwater Quality in Jingyuan County, a Semi-Humid Area in Northwest China
}

\author{
WU JIANHUA, LI PEIYUE and QIAN HUI \\ School of Environmental Science and Engineering \\ Chang' an University, No. 126 Yanta Road, Xi'an, Shaanxi, 710054, China \\ wjh2005xy@126.com
}

Received 19 August 2010; Accepted 8 November 2010

\begin{abstract}
Groundwater quality assessment is an essential study which plays an important role in the rational development and utilization of groundwater in any part of the world. In the study, groundwater qualities in Jingyuan County, in Ningxia, China were assessed with entropy weighted water quality index method. In the assessment, 12 hydrochemical parameters including chloride, sulphate, sodium, iron, $\mathrm{pH}$, total dissolved solid (TDS), total hardness (TH), nitrate, ammonia, nitrogen, fluoride, iodine and nitrite were selected. The assessment results show that the concentrations of iodine, TH, iron and TDS are the most influencing parameters affecting the groundwater quality. The assessment results are rational and are in consistency with the results of filed investigation of which both indicates the groundwater in Jingyuan County is fit for drinking.
\end{abstract}

Keywords: Water quality index, Groundwater quality assessment, Entropy weight, Jingyuan County

\section{Introduction}

Due to the non-availability of surface water, groundwater has become a major source for drinking purpose in many parts of the world. Jingyuan County, situated in the inland of China, mainly sources from groundwater and groundwater quality affects people's health significantly. During the last few decades, the demand for groundwater has been increasing because of the rapid development of urbanization and rapid growth of population. Hence, it is become more and more important and necessary to study the groundwater quality status to provide scientific basis for groundwater utilization.

The WQI method for groundwater quality assessment is widely used around the world due to the capability of fully expression of the water quality information and is one of the most effective tools and important parameters to the evaluation and management of groundwater quality. The WQI method has been used in many countries. In India, Rajankar ${ }^{1}$ calculated different groundwater sources with WQI in 22 different sites. Adriano et al. ${ }^{2}$ assessed 
the monthly water quality of the Douro River during a 10-year period with a modified nineparameter Scottish WQI. Simões et al. ${ }^{3}$ introduced WQI as a simple pollution indicator for aquaculture activity to subsidize management actions in the Médio Paranapanema Watershed in São Paulo State, Brazil. Varnosfaderany et al. ${ }^{4}$ assessed the water quality of the Zayandehrud River using National Sanitation Foundation Water Quality Index (NSF WQI). In the paper, an entropy weighted water quality index (WQI) method was applied to the groundwater quality assessment in Jingyuan County, in Ningxia, Northwest China to provide a theoretical and scientific basis for the rational development and utilization of groundwater resources and groundwater protection.

\section{Experimental}

Jingyuan County is situated in the northern Ningxia Hui Autonomous Region, east of the Liupan Mountains, between longitude $106^{\circ} 10^{\prime} \mathrm{E}$ and $106^{\circ} 30^{\prime} \mathrm{E}$ and latitude $35^{\circ} 14^{\prime} \mathrm{N}$ and $35^{\circ} 46^{\prime} \mathrm{N}$. The borders are the Pingliang City of Gansu Province in the east, Huating County and Zhuanglang County of Gansu in the south and is adjacent to Longde County in the west and Yuanzhou District and Pengyang County in the north and covers total area of $1131 \mathrm{~km}^{2}$ (Figure 1).

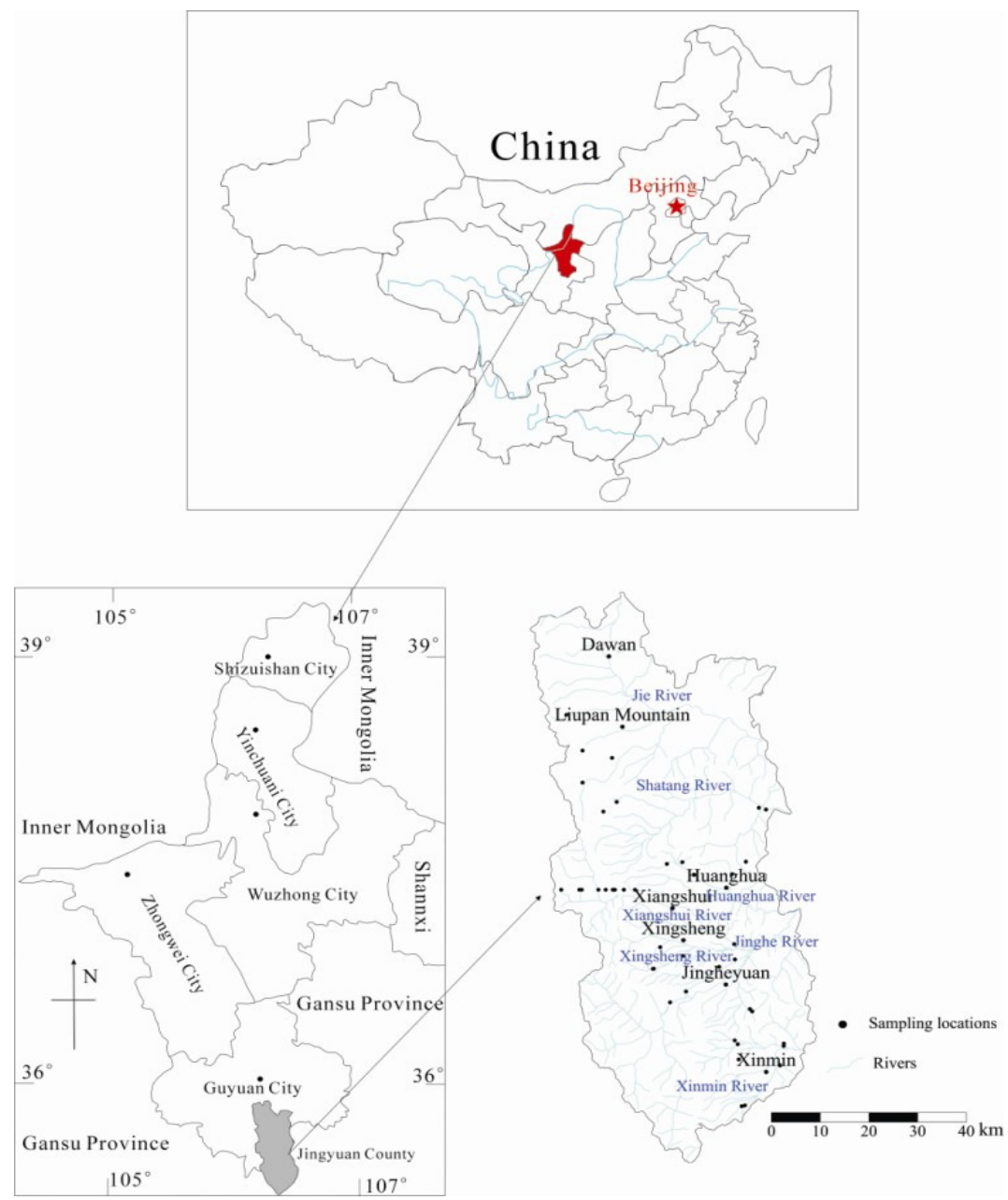

Figure 1. Location of study area 
The mean annual temperature in Jingyuan County is $5.7^{\circ} \mathrm{C}$, the highest temperature occurs in July, and the minimum temperature is in January. The mean annual precipitation in Jingyuan County is $500 \mathrm{~mm}$ and is mainly concentrated from June to September. The precipitation of the four months accounts for nearly $60 \%$ of the precipitation over the whole year. The precipitation distributes unevenly and gradual decreases from the south to the north. In the south, the precipitation is usually larger than $600 \mathrm{~mm}$, while in the north of the county, the precipitation decreases to less than $500 \mathrm{~mm}$. The average evaporation is $1500-1800 \mathrm{~mm}$.

The general characteristics of the topography in Jingyuan County are high mountains in the western part, low hills in the east and low terraces in the middle. Regional landscape can be divided into rocky mountain area formed by structural denudation, hilly area formed by structural denudation and alluvial plain formed by rivers. The rivers in Jingyuan County belong to the Jinghe River system and all the rivers originate from the mountains and run from west to east. The main rivers here include Jie River, Shatang River, Huanghua River, Xingsheng River, Xiangshui River, Jinghe River, Xinmin Creek. The rivers are shown in Figure 1.

Based on the hydraulic characteristics and storage conditions of groundwater in the region, the groundwater can be divided into the pore water in loose rocks, fracture - pore water in clastic rocks, fissure water in clastic rocks of Cretaceous and fracture-karst water in carbonate rocks and the first three types of groundwater which distribute widely in the area are the major sources for drinking and agricultural irrigation. The hydrochemical types of groundwater in the region are the $\mathrm{HCO}_{3} \cdot \mathrm{SO}_{4}-\mathrm{Ca} \cdot \mathrm{Mg}$ type and $\mathrm{HCO}_{3}-\mathrm{Ca} \cdot \mathrm{Mg}$ type.

\section{Materials}

Groundwater samples were collected from 45 different locations in August 2007. The sampling locations are shown in Figure 1. Samples were collected in pre-cleaned plastic polyethylene bottles for physicochemical analysis. Prior to sampling, all the sampling containers were washed and rinsed thoroughly with the groundwater to be taken for analysis. The samples were numbered from GW01 to GW45 before taken to the laboratory for chemical analysis. Each sample was analyzed for 20 parameters including carbonate, bicarbonate, chloride, sulphate, calcium, magnesium, sodium, potassium, iron, $\mathrm{pH}$, total dissolved solid (TDS), total hardness (TH), nitrate, ammonia nitrogen, fluoride, chroma, iodine, nitrite, metasillicio acid and free carbon dioxide by laboratory of Ningxia Geo-Environmental Monitoring Station using standard procedures recommended by Chinese Ministry of Water Resources. During sample collection, handling and preservation, standard procedures recommended by the Chinese Ministry of Water Resources were followed to ensure data quality and consistency.

\section{Entropy weighted water quality index (EWQI)}

For computing EWQI, the following steps must be followed. In the first step, an entropy weight must be assigned to each parameter ${ }^{5-9}$. The concept of information entropy was first proposed in 1948 by Shannon ${ }^{6}$ and it was regarded as the uncertainty of a stochastic event or metric of information content ${ }^{6}$. The steps for calculating entropy weight are described as follows ${ }^{9}$.

Suppose there are $m$ water samples taken to evaluate the water quality $(i=1,2, \ldots, m)$. Each sample has $n$ evaluated parameters $(j=1,2, \ldots, n)$. According to observed data, eigenvalue matrix $\boldsymbol{X}$ can be constructed:

$$
X=\left[\begin{array}{cccc}
x_{11} & x_{12} & \cdots & x_{1 n} \\
x_{21} & x_{22} & \cdots & x_{2 n} \\
\vdots & \vdots & \ddots & \vdots \\
x_{m 1} & x_{m 2} & \cdots & x_{m n}
\end{array}\right]
$$


Data pretreatment must be put into force to eliminate the influence caused by the difference of different units of characteristic indices and different quantity grades. According to attribution of every index, the feature indexes may be divided into four types: efficiency type, cost type, fixed type and interval type ${ }^{6}$. For the efficiency type, the construction function of normalization is:

$$
y_{i j}=\frac{x_{i j}-\left(x_{i j}\right)_{\min }}{\left(x_{i j}\right)_{\max }-\left(x_{i j}\right)_{\min }}
$$

While for the cost type, the construction function of normalization is:

$$
y_{i j}=\frac{\left(x_{i j}\right)_{\max }-x_{i j}}{\left(x_{i j}\right)_{\max }-\left(x_{i j}\right)_{\min }}
$$

After transform, the standard-grade matrix $\boldsymbol{Y}$ can be obtained and shown below:

$$
Y=\left[\begin{array}{cccc}
y_{11} & y_{12} & \cdots & y_{1 n} \\
y_{21} & y_{22} & \cdots & y_{2 n} \\
\vdots & \vdots & \ddots & \vdots \\
y_{m 1} & y_{m 2} & \cdots & y_{m n}
\end{array}\right]
$$

Then the ratio of index value of the $j$ index and in $i$ sample is:

$$
P_{i j}=y_{i j} / \sum_{i=1}^{m} y_{i j}
$$

The information entropy is expressed by the formula below:

$$
e_{j}=-\frac{1}{\ln m} \sum_{i=1}^{m} P_{i j} \ln P_{i j}
$$

The smaller the value of $e_{j}$ is, the bigger the effect of $j$ index. Then the entropy weight can be calculated with the below formula:

$$
\omega_{j}=\frac{1-e_{j}}{\sum_{j=1}^{n}\left(1-e_{j}\right)}
$$

In the formula, $\omega_{j}$ is defined as the entropy weight of $j$ parameter. The second step for calculating EWQI is to assign a quality rating scale $\left(q_{j}\right)$ for each parameter. The $q_{j}$ is calculated by the following formula:

$$
q_{j}=\frac{C_{j}}{S_{j}} \times 100
$$

Where $C_{j}$ is the concentration of each chemical parameter in each water sample in $\mathrm{mg} / \mathrm{L}, S_{j}$ is the limit for drinking groundwater of each parameter in $\mathrm{mg} / \mathrm{L}$ according to Quality Standards for Groundwater of China (QSGC).

The above equation ensures that if $j$ parameter is totally absent in the water, the $q_{j}$ is 0 , and when the amount of this parameter is just equal to its permissible value, the $q_{j}$ is 100 . It is a little different for the quality rating scale calculation of $\mathrm{pH}$. In the QSGC, the permissible limit of $\mathrm{pH}$ is 6.5 to 8.5 , whereas the ideal value for drinking water is 7 . Hence, the quality rating scale calculation of $\mathrm{pH}$ will be calculated with the following formula: 


$$
q_{\mathrm{pH}}=\frac{C_{\mathrm{pH}}-S_{\mathrm{I}}}{S_{\mathrm{pH}}-S_{\mathrm{I}}} \times 100
$$

Where $q_{\mathrm{pH}}$ is the quality rating scale of $\mathrm{pH}, C_{\mathrm{pH}}$ is the observed value of $\mathrm{pH}, S_{\mathrm{pH}}$ is the permissible value of $\mathrm{pH}$ in QSGC (8.5) and $S_{\mathrm{I}}$ is ideal value of $\mathrm{pH}$. The EWQI can be calculated in the third step by the formula below:

$$
E W Q I=\sum_{j=1}^{n} \omega_{j} q_{j}
$$

According to EWQI, groundwater is classified into five ranks, ranging from "excellent water" to "extremely poor water". The classification standards are listed in Table 1.

Table 1. Classification standards of groundwater quality according to EWQI

\begin{tabular}{ccc}
\hline EWQI & Rank & Water Quality \\
\hline$<50$ & I & Excellent water quality \\
$50 \sim 100$ & II & Good water quality \\
$100 \sim 150$ & III & Medium or average water quality \\
$150 \sim 200$ & IV & Poor water quality \\
$>200$ & V & Extremely poor water quality \\
\hline
\end{tabular}

\section{Results and Discussion}

\section{Water quality parameters}

TDS, affected mainly by topography, lithology of aquifer, recharge, runoff and discharge conditions of groundwater, is an important parameter for assessing groundwater quality. According to the results of sample analysis, the concentration of TDS in Jingyuan is within the range of $0.235-0.706 \mathrm{~g} / \mathrm{L}$, indicating fresh water. According to the QSGC, the permissible value of TDS for drinking water is $1000 \mathrm{mg} / \mathrm{L}$ and hence all the samples are within the limit. However, the distribution of TDS is uneven, the concentration of TDS in the northwest and north is higher than that in other parts and the concentration of TDS gradually decreases from northwest to southeast.

According to the grading standards of $\mathrm{TH}\left(\right.$ as $\left.\mathrm{CaCO}_{3}\right)$, groundwater can be divided into soft water $(\mathrm{TH}<150 \mathrm{mg} / \mathrm{L})$, moderately hard water $(150<\mathrm{TH}<300 \mathrm{mg} / \mathrm{L})$, hard water $(300<\mathrm{TH}<450 \mathrm{mg} / \mathrm{L})$, extremely hard water $(\mathrm{TH}>450 \mathrm{mg} / \mathrm{L})$. According to the results of sample analysis, the TH of all samples is within the limit of QSGC. The TH shows a similar characteristic to TDS, the highest TH occurs in the northwest part and it gradually decreases from northwest to southeast.

Fluoride $\left(\mathrm{F}^{-}\right)$is a widely distributed element in rocks. It is a necessary element for human beings. However, too much absorption of fluoride may cause people to suffer from dental fluorosis and crippling fluorosis. The feasible concentration of $\mathrm{F}^{-}$is less than 1.0 $\mathrm{mg} / \mathrm{L}$ according to QSGC. As a matter of fact, lower concentration of $\mathrm{F}^{-}$than $0.5 \mathrm{mg} / \mathrm{L}$ can also cause some disease to human body. However, the needs for $\mathrm{F}^{-}$of human body can be supplied in other ways. Hence, it is a more serious problem of excessive $\mathrm{F}^{-}$than the shortage of $\mathrm{F}^{-}$. Therefore, in the EWQI calculation, the permissible limit of $\mathrm{F}^{-}$is treated as $1.0 \mathrm{mg} / \mathrm{L}$. According to the research, the fluoride content in the study area was found to be slightly out of the permissible levels. Of all the 45 samples, only 1 sample exceeded the upper limit of the standard and the highest concentration of fluoride is $1.2 \mathrm{mg} / \mathrm{L} .37$ samples are lower than $0.5 \mathrm{mg} / \mathrm{L}$ and the minimum value is 0 . This indicates that groundwater in Jingyuan County is roughly suitable for direct consumption, but with some supply of $\mathrm{F}^{-}$in other ways. 
Iron $(\mathrm{Fe})$ is an essential element for human body and the permissible value of $\mathrm{Fe}$ in groundwater is $0.3 \mathrm{mg} / \mathrm{L}$. According to the research and analytical results of water samples, the concentration of $\mathrm{Fe}$ varies between $0.02-0.2 \mathrm{mg} / \mathrm{L}$ which indicates that the concentration of $\mathrm{Fe}$ in groundwater is suitable for human body.

Iodine $\left(\mathrm{I}^{-}\right)$is an essential element for human body too. According to the QSGC, the feasible concentration of I for human beings is $10-50 \mu \mathrm{g} / \mathrm{L}$. Too much intake or shortage of $\mathrm{I}^{-}$can cause serious disease to human body. The analytical results of water samples show that the maximum value of $\mathrm{I}^{-}$is $40 \mu \mathrm{g} / \mathrm{L}$ and the minimum value of $\mathrm{I}^{-}$is $20 \mu \mathrm{g} / \mathrm{L}$, which indicates that the concentration of $\mathrm{I}^{-}$is within the limit of QSGC.

\section{Entropy weighted water quality index}

The EWQI was calculated with the methods and steps mentioned above. The entropy weight and EWQI are listed in Table 2 and Table 3.

Table 2. Entropy weight of hydrochemical parameters

\begin{tabular}{ccccccc}
\hline Item & $\mathrm{pH}$ & $\mathrm{TH}$ & $\mathrm{Na}^{+}$ & $\mathrm{TDS}$ & $\mathrm{SO}_{4}{ }^{2-}$ & $\mathrm{Cl}^{-}$ \\
\hline Information entropy, $e j$ & 0.987 & 0.972 & 0.991 & 0.977 & 0.979 & 0.982 \\
Entropy weight, $w j$ & 0.059 & 0.126 & 0.040 & 0.105 & 0.097 & 0.082 \\
\hline Item & $\mathrm{Fe}$ & $\mathrm{NO}_{3}{ }^{-}$ & $\mathrm{NO}_{2}{ }^{-}$ & $\mathrm{NH}_{4}^{+}$ & $\mathrm{F}^{-}$ & $\mathrm{I}$ \\
\hline Information entropy, $e j$ & 0.973 & 0.986 & 0.986 & 0.994 & 0.991 & 0.963 \\
Entropy weight, wj & 0.124 & 0.065 & 0.064 & 0.027 & 0.041 & 0.170 \\
\hline
\end{tabular}

Table 3. EWQI of water samples and water quality ranking

\begin{tabular}{ccccccccc}
\hline No. & EWQI & Rank & No. & EWQI & Rank & No. & EWQI & Rank \\
\hline GW01 & 32.06 & I & GW16 & 26.38 & I & GW31 & 31.64 & I \\
GW02 & 48.54 & I & GW17 & 35.97 & I & GW32 & 36.51 & I \\
GW03 & 42.89 & I & GW18 & 34.92 & I & GW33 & 48.23 & I \\
GW04 & 58.93 & II & GW19 & 38.35 & I & GW34 & 35.85 & I \\
GW05 & 47.67 & I & GW20 & 28.59 & I & GW35 & 41.45 & I \\
GW06 & 45.00 & I & GW21 & 29.37 & I & GW36 & 32.47 & I \\
GW07 & 31.94 & I & GW22 & 30.59 & I & GW37 & 37.43 & I \\
GW08 & 47.34 & I & GW23 & 30.74 & I & GW38 & 42.59 & I \\
GW09 & 53.05 & II & GW24 & 31.31 & I & GW39 & 41.97 & I \\
GW10 & 45.54 & I & GW25 & 46.14 & I & GW40 & 33.43 & I \\
GW11 & 39.16 & I & GW26 & 30.42 & I & GW41 & 37.05 & I \\
GW12 & 27.16 & I & GW27 & 32.18 & I & GW42 & 39.86 & I \\
GW13 & 33.65 & I & GW28 & 33.74 & I & GW43 & 29.49 & I \\
GW14 & 36.88 & I & GW29 & 42.74 & I & GW44 & 32.05 & I \\
GW15 & 47.57 & I & GW30 & 31.08 & I & GW45 & 38.53 & I \\
\hline
\end{tabular}

It can be seen from the Table 2 that the concentrations of $\mathrm{I}^{-}$, TH, Fe and TDS are the most influencing parameters affecting the groundwater quality. The weights of the four parameters are larger than 0.1 , whereas others are less than 0.1 . This means that the groundwater assessment results are greatly affected by the concentrations of the four parameters.

The EWQI of water samples vary between 26.38 and 58.93 and only the EWQI of sample GW04 and GW09 exceed 50, belonging to good quality water and others are less than 50, belonging to extremely good quality water, which is in consistency with the results of filed investigation. The EWQI for all the samples are smaller than 100 and the groundwater qualities in Jingyuan County are fit for drinking. 


\section{Conclusion}

This study assessed the groundwater quality in Jingyuan County, northwest China with entropy weighted water quality index. The entropy weights of hydrochemical parameters show that the concentrations of $\mathrm{I}^{-}, \mathrm{TH}, \mathrm{Fe}$ and TDS are the most influencing parameters affecting the groundwater quality and the groundwater quality assessment results are greatly affected by the four parameters. The calculation of EWQI shows that the EWQI method is an easy to use method for groundwater quality assessment and the assessment results are rational and are in consistency with the results of filed investigation. The results also show the groundwater in Jingyuan County is fit for drinking.

\section{Acknowledgment}

This research project was supported by the National Natural Science Foundation of China (Grant No. 40772160). Authors also would like to thank the editor and anonymous reviewers for their useful comments on this paper.

\section{References}

1 Rajankar P N, Gulhane S R and Tambekar D H, Ramteke D S and Wate S R, E-J Chem., 2009, 6(3), 905-908.

2 Adriano A B, Rita T and William J W, Environ Manage, 2006, 38, 910-920.

3 Simões F S, Moreira A B, Bisinoti M C, Gimenez S M N and Yabe M J S, Ecological Indicators, 2008, 8(5), 476-484.

4 Varnosfaderany M N, Mirghaffary N and Ebrahimi E, Soffianian A, Wat Sci Technol., 2009, 60(9), 2319-2327.

5 Men B H, Fu Q and Zhao X M, J Northeast Agricultural University, 2004, 11(1), 66-68.

6 Ding S F and Shi Z Z, J Information Sci., 2005, 31 (6), 497-502.

$7 \quad$ Liu R T, Fu Q and Gai Z M, J Northeast Agricultural University, 2007, 14(4), 368-373.

8 Chen S Z, Wang X J and Zhao X J, J China University of Mining and Technology, 2008, 18 (1), 72-75.

9 Li P Y, Qian H and Wu J H, E-J Chem., 2010, 7(S1), S209-S216. 


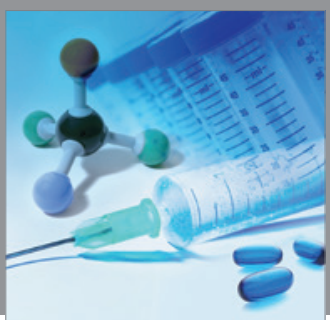

International Journal of

Medicinal Chemistry

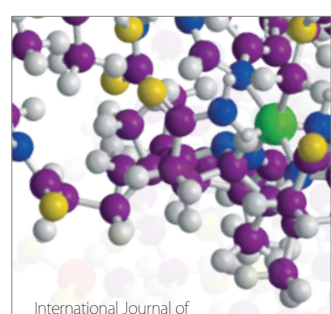

Carbohydrate Chemistry

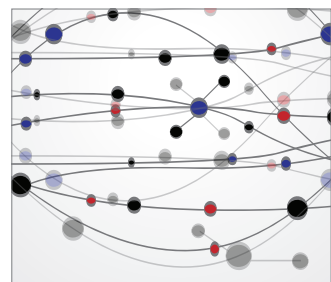

The Scientific World Journal
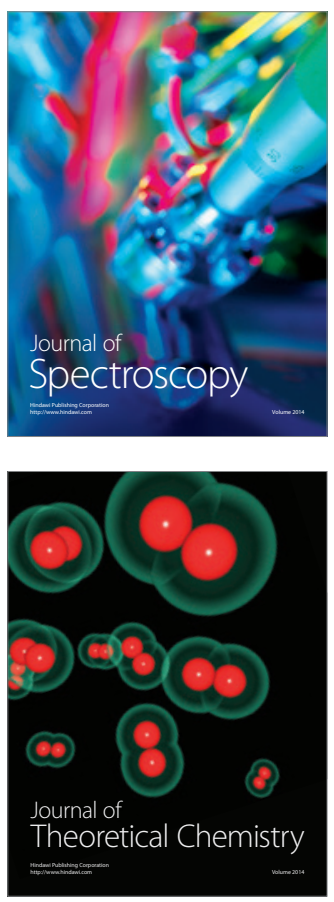
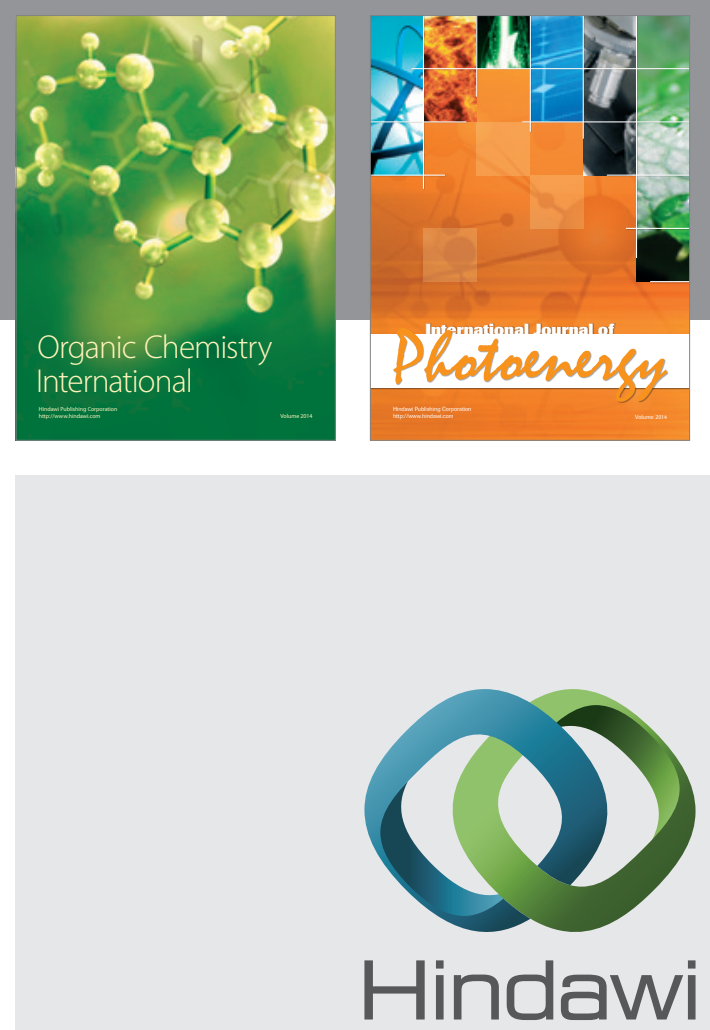

Submit your manuscripts at

http://www.hindawi.com
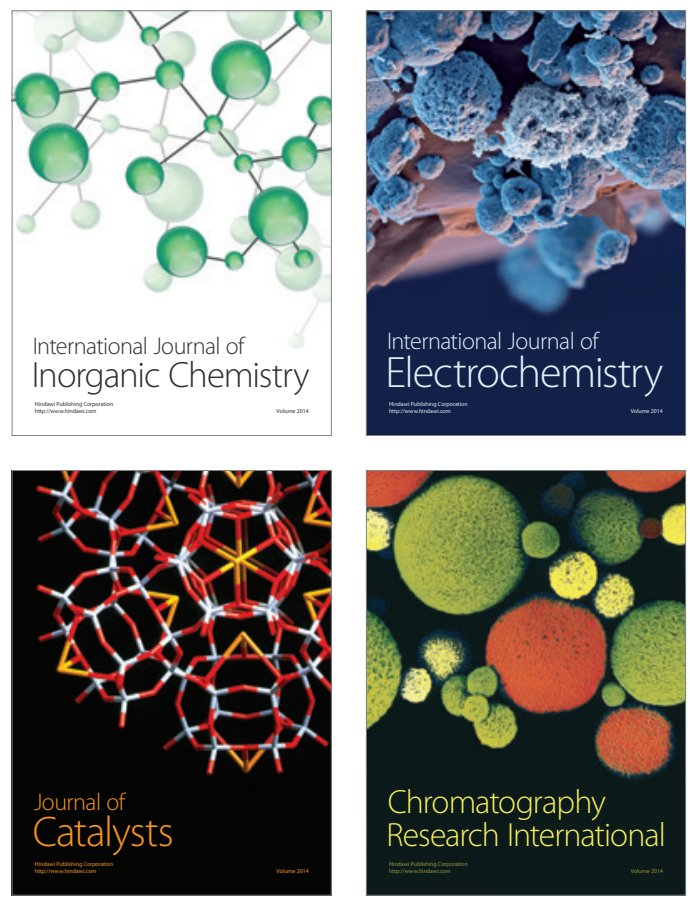
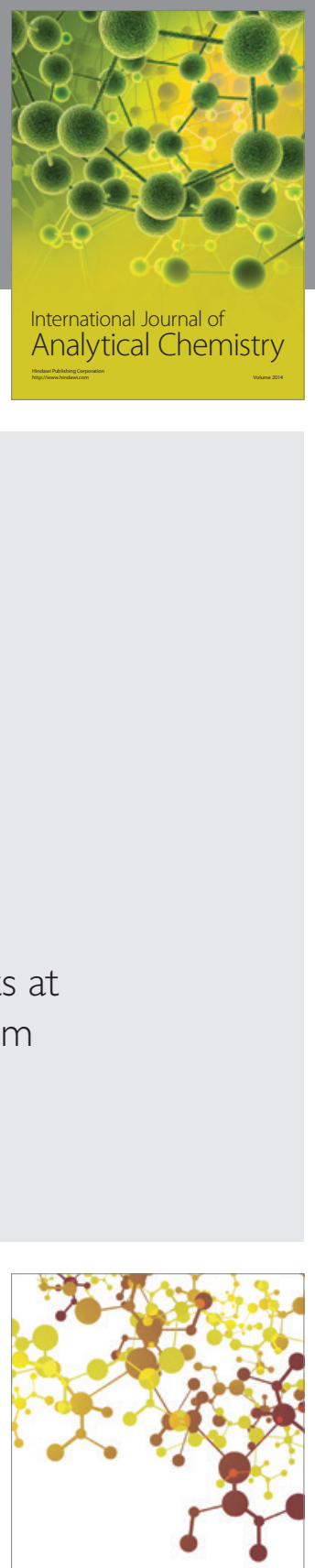

Journal of

Applied Chemistry
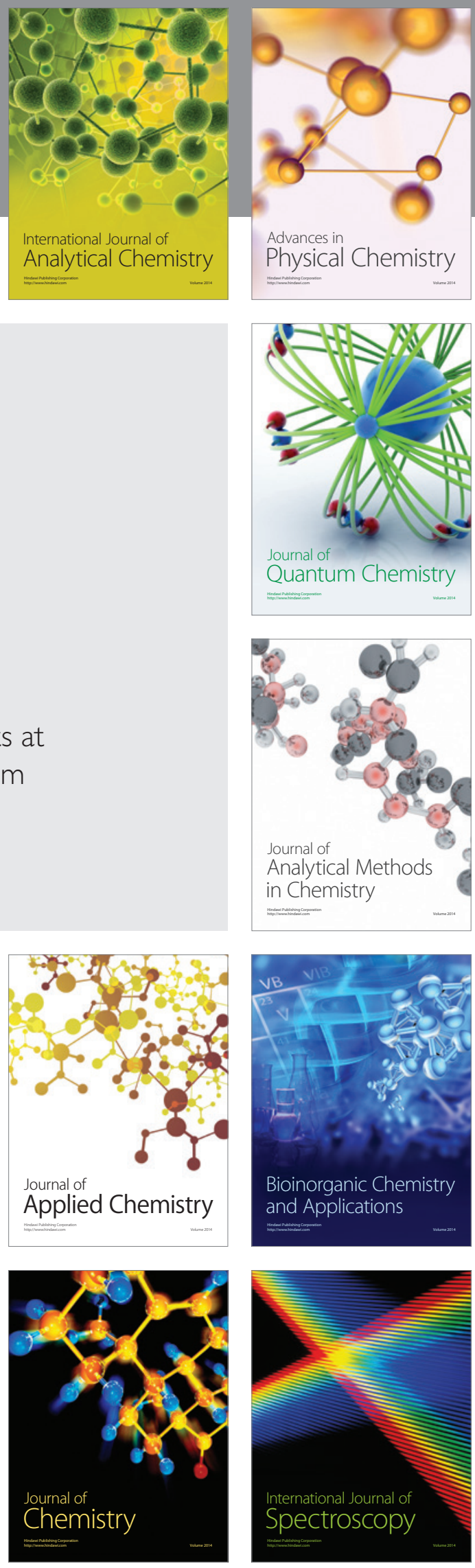